\section{Cancer endocrinology: noticeable developments in the last decade}

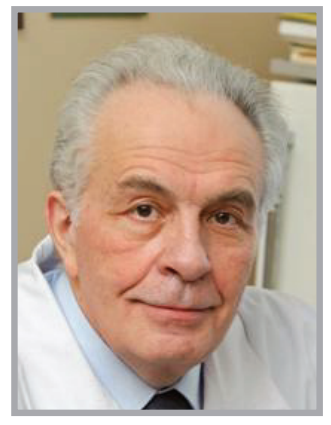

Lev M Berstein*

\author{
"As a whole, even such a short review of \\ contemporary cancer endocrinology in its \\ fundamental and applied aspects can show that \\ the achievements and opportunities in this area \\ can earn it appropriate place in 'Future Oncology', \\ as a subject and as a journal, which in a last \\ decade rightly became popular and demanded."
}

The past 10 years have been rich in new developments, potentially leading to important breakthroughs in many areas of science. In many respects, this also applies to the subject of this small editorial, devoted to endocrinology of cancer.

Of course, the author could not mention all researchers and subjects worth mentioning, as the references list length is finite. Therefore, we ask readers to be excused in case some important article is omitted and certain topics are not covered. While shaping this editorial, we aimed to first of all mention hormonedependent neoplasms, then neuroendocrine tumors and finally, personalized medicine with its emphasis on molecular and genetic markers for patient stratification.

When discussing different hormonedependent cancers and their social impact, the most important is undoubtedly breast cancer (BC). However, prostate cancer and endometrial cancer (EC) have recently become nearly as important due to the stably high incidence of the first and because of morbidity gain of the latter, which is based, at least partly, on its association with obesity [1].
Most progress in $\mathrm{BC}$ research was made in the development of its molecular classification. In the field of $\mathrm{BC}$ endocrinology and hormonal therapy response, we would like to mention the research by Horwitz et al. These authors demonstrated luminal BC heterogeneity due to a small population of ER-PR- cells present in $\mathrm{ER}^{+} \mathrm{PR}^{+}$tumor tissue. As a consequence, in vitro results suggest that therapy of tumors containing so-called pure luminobasal cells can be enhanced due to the addition of antiestrogens and EGFR inhibitors [2]. There is also a growing body of molecular data (obtained in particular by miRNA profiling methods) in favor of BC diversity, which makes one suppose an even wider range of $\mathrm{BC}$ subtypes with different sensitivity to hormone therapy [3]. The interaction between miRNA and ER is itself drawing much attention since this interaction is probably one of the most important regulatory mechanisms defining estrogen signaling, BC cells receptor phenotype and treatment response [4]. The miRNA research seems to hold as much promise in this area as progenitor and stem cells studies [4] and, indeed, in the last decade many reports have continued to elucidate the latter subject.
*Lab. Oncoendocrinology, NN Petrov Research Institute of Oncology, Pesochny-2, St Petersburg 197758, Russia; Tel.: +7 812439 9536; Fax: +7 812596 8947; levmb@endocrin.spb.ru

\section{KEYWORDS}

- cancer • endocrinology

- hormone • present and future of oncology

\section{“The past 10 years have been rich in new developments, potentially leading to important breakthroughs in many areas of science."}

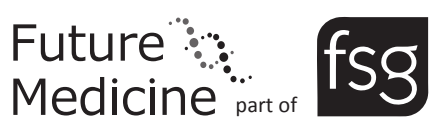


The role of stem cells in mammary carcinogenesis and their possible connection to hormonal signaling has been analyzed in patients with hereditary $\mathrm{BC}$, among other areas. For rather a long time, BRCA1-associated $\mathrm{BC}$ was considered nearly equal to triple-negative $\mathrm{BC}$ variants featuring a common progenitor substrate, basal (myoepithelial) cells of mammary epithelium. The data acquired in the last $4-5$ years challenge this concept via promoting the role of luminal progenitors $[5,6]$. Among other consequences, this shows the need for a more careful examination of the role of estrogen component (taking into account in particular progenotoxic fractions of estrogens and catechol estrogens metabolites) and its potential involvement in $\mathrm{BC}$ carcinogenesis in patients with $B R C A 1$ mutations [7].

We wish to remind that estrogens, which still hold their strong positions in BC carcinogenesis in spite of androgens and other hormone and hormone-like factors 'incursion', could be endogenous (also synthesized by the mammary gland) and exogenous. The last decade gave some important information for a long-lasting discussion on whether estrogens given to menopausal women are a risk factor for BC or not. In spite of minor disagreements, most researchers think the 'pure' estrogens are less dangerous (mostly due to their ability of apoptosis enhancement) than their combination with progestins, although there are no clear recommendations yet for the timing and duration of estrogen-containing medicine usage [8]. It is justified to mention here the increasingly popular notion on the postmenopausal hormone therapy problastomogenic effect being a result of preexisting occult undiagnosed BC stimulation [9]. Another innovation is the use of the combination of conjugated estrogens and bazedoxifene (antiestrogen), which in theory should not increase BC or EC risk, while offering all the benefits of postmenopausal estrogen therapy (e.g., vasomotor symptoms attenuation and lipidemia control) [10].

As already mentioned, the connection between EC and obesity (which lately became more important due to obesity epidemic) is another sign of the role of endocrinology in endometrial cancer research. Meanwhile, adjuvant hormone therapy (e.g., with progestins, tamoxifen or aromatase inhibitors) is practically not used in EC patients, and pathologists do not routinely screen this tumor samples for estrogen and progesterone receptors. Nevertheless, although hormone therapy (with exception of progestin use in metastatic disease) is much less effective in EC than in $\mathrm{BC}$, it should not be completely forgotten and could take into account steroid as well as nonsteroidal targets [11,12]. Another important point has been recently demonstrated in the relative similarity between EC type I and II hormonerelated risk factors, which previously appeared to be greater than indicated [13]. This conclusion also supports the need for further revision of EC classification based on molecular and genetic data without limiting the number of EC variants to the two well-known variants [14]. This classification could distinguish several new EC types with distinct sensitivity to hormone therapy. In regards to paracrine and endocrine aspects, attention is also focused on the adipose-stromal cells and their products, which seem to play an important role in EC growth and metastasizing, especially in obese patients [15].

The latter findings once again underline the role of obesity and conditions commonly associated with it (metabolic syndrome, insulin resistance, diabetes mellitus Type 2). These conditions are now so common that we could talk of 'noncommunicable pandemic'. This pandemic can influence the risk and clinicomorphological characteristics of some tumors arising from hormonedependent tissues. The prevalence of mentioned conditions is also important as indirect markers of the effectiveness of the usage of antidiabetic drugs (in particular, metformin), weight-reducing medications and other medicines helping contemporary humans escape this peculiar 'metabolic prison'. Unfortunately, the obesity problem is not likely to be resolved soon despite all the large-scale measures taken by the WHO [16] and discussions by cancer endocrinologists in recent decades. A relatively new area we should mention is the heterogeneity of obesity, which may influence the mode of its association with cancer [17].

There is also another characteristic factor, namely the 'tissue or organ specificity' of obesity-related and diabetes-related cancers. For example, while diabetes mellitus Type 2 is an important risk factor for some tumors (cancer of liver, pancreas and endometrium, among others), it has no influence on BC incidence in premenopausal females and even has a negative correlation to prostate cancer risk, which is probably due to lower androgens and IGFBP-3 levels in circulation [18]. No doubt, the last decade has seen increased interest in prostate cancer including issues such as the role of estrogens, the 
importance of cancer-repopulating and castrateresistant cells, hormone-metabolic consequences of complete androgenic blockade and the discovery of the new antiandrogens, among others $[19,20]$. As a whole, one can talk about reaching a new milestone of research in this interesting area of cancer endocrinology.

Neuroendocrine tumors (NET) are a heterogeneous group of malignant conditions, most of which (except carcinoids) occur quite rarely. On the other hand, in the last few years we witnessed a rapid increase in NET patients' population, which is probably explained not only by higher morbidity but is also due to more effective diagnostic procedures. Medical centers are able now to evaluate a whole spectrum of hormones and hormone-like compounds and have access to advanced morphological, visualizing and genetic techniques. This could help clarify some causes of NET, evaluate its risk factors and develop effective conservative therapy, such as mTOR inhibitors, although the main role is still played by surgery [21]. There is evidence of growing interest to this subject which is reflected in increased number of publications and even the issuing of new specialized journals, in particular International Journal of Endocrine Oncology.

A lot could be written here about thyroid cancer (TC), but we are obliged to mention only several important topics. Among them are the growing incidence of well-differentiated TC (due to papillary carcinomas and more effective diagnostic procedures for microcarcinomas), attempts to overcome TC resistance to radioiodine therapy (taking into account $B R A F$ mutations as well as FoxP3 and NIS expression) and an increasing number of papers on obesity/insulin resistance as TC risk factors and adverse prognostic markers [22]. There were some interesting publications on colorectal cancer endocrinology in connection with obesity, diabetes and insulin-like growth factors, although in our opinion this topic deserves much more attention. The mere fact of this tumor being a target for gastrointestinal hormones [23] gives us hope of finding ways of colorectal cancer hormonal or antihormonal therapy and prevention able to complement modern methods (surgery, irradiation and targeted therapy).

As a whole, even a such short review of contemporary cancer endocrinology in its fundamental and applied aspects can show that the achievements and opportunities in this area can earn it appropriate place in 'Future Oncology', as a subject and as a journal, which in a last decade rightly became popular and demanded.

\section{Financial \& competing interests disclosure}

The author has no relevant affliations or financial involvement with any organization or entity with a financial interest in or financial conflict with the subject matter or materials discussed in the manuscript. This includes employment, consultancies, honoraria, stock ownership or options, expert testimony, grants or patents received or pending, or royalties.

No writing assistance was utilized in the production of this manuscript.

\section{References}

1 Zhang Y, Liu H, Yang S, Zhang J, Qian L, Chen X. Overweight, obesity and endometrial cancer risk: results from a systematic review and meta-analysis. Int. J. Biol. Markers. 29(1), e21-e29 (2014).

2 Knox AJ, Scaling AL, Pinto MP et al. Modeling luminal breast cancer heterogeneity: combination therapy to suppress a hormone receptor-negative, cytokeratin 5-positive subpopulation in luminal disease. Breast Cancer Res. 16(4), 418 (2014).

3 Bhattacharyya M, Nath J, Bandyopadhyay S. MicroRNA signatures highlight new breast cancer subtypes. Gene 556(2), 192-198 (2015).

4 Manavathi B, Dey O, Gajulapalli VN, Bhatia RS, Bugide S, Kumar R. Derailed estrogen signaling and breast cancer: an authentic couple. Endocr. Rev. 34(1), 1-32 (2013).
5 Molyneux G, Geyer FC, Magnay FA et al. BRCA1 basal-like breast cancers originate from luminal epithelial progenitors and not from basal stem cells. Cell Stem Cell 7(3), 403-417 (2010).

6 Leccia F, Del Vecchio L, Mariotti E et al. ABCG2, a novel antigen to sort luminal progenitors of BRCA1- breast cancer cells. Mol. Cancer. 13, 213 (2014).

7 Savage KI, Matchett KB, Barros EM et al. BRCA1 deficiency exacerbates estrogeninduced DNA damage and genomic instability. Cancer Res. 74(10), 2773-2784 (2014).

8 Manson JE, Chlebowski RT, Stefanick ML et al. Menopausal hormone therapy and health outcomes during the intervention and extended poststopping phases of the Women's Health Initiative randomized trials. JAMA 310(13), 1353-1368 (2013).
9 Santen RJ. Menopausal hormone therapy and breast cancer. J. Steroid Biochem. Mol. Biol. 142, 52-61 (2014).

10 Komm BS, Mirkin S. An overview of current and emerging SERMs. J. Steroid Biochem. Mol. Biol. 143, 207-222 (2014).

11 Berstein L. Aromatase inhibitors beyond breast cancer: endometrium versus breast puzzle and other issues. In: Resistance to Aromatase Inhibitors in Breast Cancer. Larionov A (Ed.). Springer International Publishing, Switzerland (2015).

12 Schmandt RE, Iglesias DA, Co NN, Lu KH. Understanding obesity and endometrial cancer risk: opportunities for prevention. $A m$. J. Obstet. Gynecol. 205(6), 518-525 (2011).

13 Setiawan VW, Yang HP, Pike MC et al. Type I and II endometrial cancers: have they different risk factors? J. Clin. Oncol. 31(20), 2607-2018 (2013). 


\section{EDITORIAL Berstein}

14 Cancer Genome Atlas Research Network, Kandoth C, Schultz $\mathrm{N}$ et al. Integrated genomic characterization of endometrial carcinoma. Nature 497(7447), 67-73 (2013).

15 Freese KE, Kokai L, Edwards RP et al. Adipose-derived stems cells and their role in human cancer development, growth, progression, and metastasis: a systematic review. Cancer Res. 75(7), 1161-1168 (2015).

16 Clark J. Medicalization of Global Health 3: the medicalization of the non-communicable diseases agenda. Glob. Health Action 7, 24002 (2014).
17 Berstein LM. Cancer and heterogeneity of obesity: a potential contribution of brown fat. Future Oncol. 8(12), 1537-1548 (2012).

18 Tsilidis KK, Allen NE, Appleby PN et al. Diabetes mellitus and risk of prostate cancer in the European prospective investigation into cancer and nutrition. Int. J. Cancer. 136(2), 372-381 (2015).

19 Taylor RA, Toivanen R, Risbridger GP. Stem cells in prostate cancer: treating the root of the problem. Endocr. Relat. Cancer. 17(4), R273-R285 (2010).

20 Brooke GN, Powell SM, Lavery DN et al. Engineered repressors are potent inhibitors of androgen receptor activity. Oncotarget 5(4), 959-969 (2014).

21 Young K, Iyer R, Morganstein D, Chau I, Cunningham D, Starling N. Pancreatic neuroendocrine tumors: a review. Future Oncol. 11(5), 853-864 (2015).

22 Pitoia F, Abelleira E, Bueno F, Urciuoli C, Schmidt A, Niepomniszcze H. Insulin resistance is another factor that increases the risk of recurrence in patients with thyroid cancer. Endocrine 48(3), 894-901 (2015).

23 Maddalo G, Spolverato Y, Rugge M, Farinati F. Gastrin: from pathophysiology to cancer prevention and treatment. Eur. J. Cancer Prev. 23(4), 258-263 (2014). 